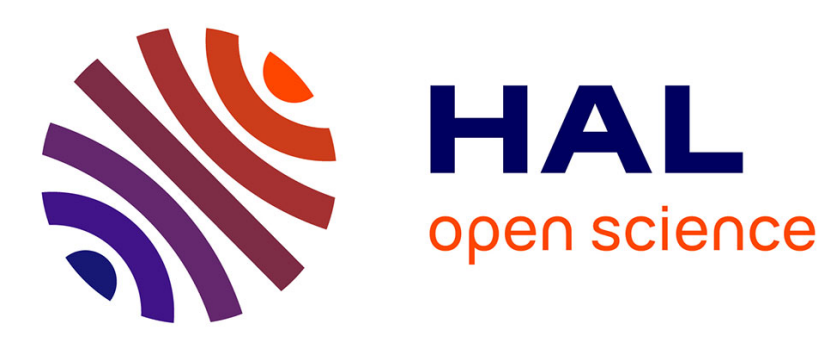

\title{
NEUTRON STUDIES OF PRETRANSITIONAL FLUCTUATIONS ABOVE STRUCTURAL TRANSITIONS IN METALS
}

\author{
S. Moss
}

\section{- To cite this version:}

S. Moss. NEUTRON STUDIES OF PRETRANSITIONAL FLUCTUATIONS ABOVE STRUCTURAL TRANSITIONS IN METALS. Journal de Physique Colloques, 1977, 38 (C7), pp.C7-440-C7443. 10.1051/jphyscol:1977787 . jpa-00217290

HAL Id: jpa-00217290

https://hal.science/jpa-00217290

Submitted on 1 Jan 1977

HAL is a multi-disciplinary open access archive for the deposit and dissemination of scientific research documents, whether they are published or not. The documents may come from teaching and research institutions in France or abroad, or from public or private research centers.
L'archive ouverte pluridisciplinaire HAL, est destinée au dépôt et à la diffusion de documents scientifiques de niveau recherche, publiés ou non, émanant des établissements d'enseignement et de recherche français ou étrangers, des laboratoires publics ou privés. 


\title{
NEUTRON STUDIES OF PRETRANSITIONAL FLUCTUATIONS ABOVE STRUCTURAL TRANSITIONS IN METALS
}

\author{
S. C. MOSS
}

Physics Department, University of Houston, Houston, Texas 77004, U.S.A.

\begin{abstract}
Résumé. - Les transitions de phase structurales dans les métaux 3-d mettent en jeu des transformations simples (de Burgers) entre les structures bien connues, $\mathrm{cfc}, \mathrm{cc}$, hc, et la phase métastable oméga. Ces changements cristallographiques sont accompagnés de cisaillements macroscopiques variés et de déplacements microscopiques dépendant du type de changements de symétrie mis en jeu. La plupart de ces transitions sont du $1^{\mathrm{er}}$ ordre, cependant, et l'on continue de chercher jusqu'à quel point on peut décrire de tels changements de phase sur la base d'une dynamique de réseau. La diffraction de neutron, associée aux études de rayons $\mathrm{X}$, est en principe l'outil idéal pour attaquer ce problème, et on a mis en évidence dans certains de ces systèmes, l'existence de mode mou et/ou de fluctuations prétransitionnelles. Cependant, la majorité de ces systèmes ne présentent pas de comportement de mode mou dramatique, comme il se manifeste, par exemple, dans $\mathrm{Nb}_{3} \mathrm{Sn}$, et dans de nombreux cas, la réponse dynamique de réseau apparaît normale. Il est fait aussi brièvement allusion à l'influence des défauts sur la diffusion des neutrons.
\end{abstract}

\begin{abstract}
Structural phase transitions in (3-D) metals usually involve simple (Burgers) transformations among the well known structures, fcc, bcc, hcp and metastably, the omega phase. Accompanying these crystallographic changes are various macroscopic shears and microscopic shuffles depending upon what kinds of symmetry changes are ultimately involved. Most of the transitions are first order, however, and it has been of continuing interest to explore the extent to which a lattice dynamical basis can be given to such phase changes. Neutron scattering, coupled with X-ray studies, is in principle an ideal tool for looking at this problem and limited evidence exists for mode softening and/or pretransitional fluctuations in some of these systems. The majority of systems do not, however, exhibit dramatic soft mode behavior, as is seen, for example, in $\mathrm{Nb}_{3} \mathrm{Sn}$, and in many cases the lattice dynamical response appears normal. The influence of defects on the neutron scattering is also briefly alluded to.
\end{abstract}

1. Introduction. - There are two vintage papers on structural phase transformations in simple metals that have recently been revived by the possibility of studying the physical origin of these transformations more microscopically using inelastic neutron scattering. These papers are by Burgers [1] and Zener [2]. The first outlines the relatively simple atomic displacements involved in transforming from bce to fcc or hcp. It is then straightforward to rewrite Burgers' displacements in terms of static or condensed phonons and this was discussed by Moss, Keating and Axe [3], vis-à-vis the competitive transformations in $\mathrm{Zr}$ between bcchcp and bec-omega. The second paper by Zener discusses both the stability of bcc (it is due primarily to the vibrational entropy associated with a high density of states which is due, in turn, to the lowlying transverse modes) and the origin of the lowlying transverse modes. In a sense, Zener presents the foundation for much of our understanding of stability as he discusses the (110): (1110) shear constant for bcc or $\beta$ phase metals. To quote Zener : The anomalously low value of the $\left(C_{11}-C_{12}\right) / 2$ shear coefficient of $\beta$-brass may readily be seen to be a direct consequence of the combination of a body-centered cubic lattice with ions containing only closed shells. Thus a bodycentered cubic packing of balls manifests no resistance to a simple $(110)(\overline{1} 10)$ shear. This lack of shear resistance is a consequence of the fact that such a shear leaves the distance between closest neighbors unchanged to a first approximation. He then goes on to a consideration of the electronic basis for the $\beta$ phase stability suggested by Fuchs [4] and Mott and Jones [5]. It is clearly an old problem and an especially interesting one since the martensitic transformation temperature in most alloy systems is a precipitously dramatic function of chemical (electron) concentration [6].

In another context, we know, of course, that a bcc lattice with nearest neighbor central forces is unstable with respect to shear waves. It is also intesting to note, as demonstrated by Price et al. [7], that boc metals, such as the alkalais, have an intrinsic longitudinal softness at the position $\sim 2 / 3(111)$, which is equivalent to a zone boundary shear softness at $1 / 3$ (112). This, too, is a simple property of bcc arising from the Coulombic contribution to phonon dispersion from a bcc lattice of point ions immersed in a neutralizing 
electron gas. In the alkalais this reciprocal lattice position, $2 / 3(111)$, is a saddle point with respect to the phonon frequencies - a minimum in (111) but a maximum in (112). In $\mathrm{V}, \mathrm{Nb}$ and $\mathrm{Ta}$, the minimum at $2 / 3(111)$ is an absolute minimum [8] and is the position, first noted by de Fontaine [9], for the Bragg peaks of the metastable omega phase.

There are, of course, other metallurgical transformations besides the bec instabilities but many of these have in common either a nearly boc structure such as the $\mathrm{CsCl}$ phases, or a softness in (110): (110). In this brief review we will include several of these cases as well as references to other transformations - some, more complicated. In all cases it is the triple axis neutron technique which, by permitting the study of a particular phonon or branch of phonons through the direct measurement of both energy and momentum transfer, is so powerful in elucidating mechanism. $\mathrm{X}$-ray scattering cannot resolve thermal energies and X-ray streaks may thus be due either to static or dynamic fluctuations. Neutron measurements resolve this at least on a time scale for the fluctuations shorter than $\sim 10^{-9} \mathrm{~s}$. This still leaves a lot of room for fluctuations which are static with respect to neutron scattering but otherwise rather short lived!

2. The bcc-hcp/omega transition. - The papers in this conference by Sanchez and de Fontaine [10] and by Cook et al. [11] discuss the omega transition in alloys which are based on $\mathrm{Ti}, \mathrm{Zr}$ and $\mathrm{Hf}$. There is a competition between hcp and omega that the present author and co-workers have discussed [3, 12] and for the present it is useful mainly to summarize our understanding of at least the $\mathrm{Zr}-\mathrm{Nb}$ neutron results $[12,13]$. In crystals of both $\mathrm{Zr}-20 \% \mathrm{Nb}$ and $\mathrm{Zr}-8 \% \mathrm{Nb}$, there are long lived fluctuations above the metastable omega transformation temperature that appear elastic (with the noted proviso of before) and that possess the local structure of, say, a particle of omega coherently embedded in bcc. The lattice dynamics of the bcc lattice are very anharmonic and hard to measure because of the very broad neutron groups (short phonon lifetimes) at all but small wave vectors. They contain mixed contributions from the internal vibrations of the slowly fluctuating omega regions as well as from the normal bcc. In other words, not only does the elastic diffuse scattering show noncubic symmetry but so does the (nominally) one phonon scattering. The picture that emerges is, as Cook has suggested [14], a coherent omega fluctuation pinned in size by a mismatch between the wave vector for the elastic energy minimum and the ideal omega structure. In this case, i.e., bcc-omega, the neutron scattering reveals no particular mode softening but rather large anharmonicity and an elastic central peak in the vicinity of the omega wave vector.

For the bcc-hcp transition, the indication from below the transformation (in the hcp phase) is of a pronounced softening of $C_{66}$ [15]. But the neutron scattering [3] shows only a uniform lowering of the $(10.0):(11.0)$ branch as the transformation temperature is approached from below. There is no particular zone boundary softness, no anharmonicity and no elastic scattering or central peak intensity.

3. $\beta$ brass-(Au, Cu) Zn, NiTi and AuCd. - $\beta$ brass has, as noted by Zener, one of the lowest values of $C^{\prime}=\left(C_{11}-C_{12}\right) / 2$ of any metal and has a strongly concentration dependent value of the martensite start temperature [16]. The availability of a large, compositionally uniform, crystal therefore prompted a largely unsuccessful neutron investigation of the dynamics of the pretransitional state [17]. The conclusion was drawn that any premonitory or pretransitional fluctuations do not appear in the normal phonon coordinates.

In the Heusler alloys $\mathrm{Au}_{x} \mathrm{Cu}_{0.53-x} \mathrm{Zn}_{0.47}$, Murakami [18] has shown a very dramatic softening, over the $\beta \mathrm{CuZn}$ value, at about $x=0.25$. At this composition $C^{\prime}=\left(C_{11}-C_{12}\right) / 2$ goes essentially to zero (interested readers are directed to his paper in which lattice softening, thermoelasticity and phase stability are all discussed). Following this work, Mori et al. [19] studied the crystal $\mathrm{Au}_{0.23} \mathrm{Cu}_{0.30} \mathrm{Zn}_{0.47}$ with neutrons demonstrating an extremely soft transverse (110):(110) branch with an additional temperature dependent softening at $\sim 2 / 3(110)$ reminiscent perhaps of a temperature dependent Kohn anomaly in a lower dimensional system. Mori $e t$ al. show that this softness at $2 / 3(110)$ can be related to an incipient metastable $3 \mathrm{R}$ structure which forms on quenching. The softening never, however, goes to zero and this is not a true soft mode transition. The authors do note, however, that $2 / 3(110)$ corresponds to a wave vector, $2 \mathbf{k}_{\mathbf{F}}$, which spans particularly flat pieces of Fermi surface again associated with electronic effects (screening and correlation) and the Kohn effect.

The introduction of the shear whose wave vector is $2 / 3(110)$, polarized in (T10), is also discussed for NiTi and AuCd by Vatanayon and Hehemann [20] in their review of diffuse X-ray and electron diffraction evidence for premartensitic effects in $\beta$-phase alloys. While this is not neutron scattering there is still revealed strong temperature dependent streaking associated with both a $2 / 3$ (111) longitudinal wave (the omega wave) and a $2 / 3$ (110) shear wave. The diffraction evidence comes largely from Sandrock et al. [21] with an analysis by Hehemann and Sandrock [22] and there is additional, dynamical (ultrasonic) support from Pace and Saunders for NiTi [23]. To date there has not been any neutron study of NiTi to our knowledge and no neutron scatterer of even moderate sanity would attempt AuCd because of absorption effects.

4. In-TI alloys. - We only mention these alloys as excellent neutron candidates because of the work of Gunton and Saunders [24] and Murakami [25]. The transformation is from fcc to fct and seems to be 
initiated again by a softness in $C^{\prime}=\left(C_{11}-C_{12}\right) / 2$ although for fcc this is not an intrinsically soft direction. The theory is developed by both sets of authors and involves both model potential calculations of phase stability and a more phenomenological Laudau treatment.

5. fec-hep in Co and its alloys. - The fcc-hcp transition is an interesting one involving a closepacked to close-packed phase. Because the fcc stacking is $A B C, A B C$ while hop is $A B, A B$ a plane must interact directly with at least its second neighbor in order to choose the correct (non-degenerate) closepacked ground state. Direct evidence for a dynamical basis for the transformation fcc-hcp in Co-7 wt pct Fe was provided by Bokshtein et al. [26] who showed a substantial decrease in the Mossbauer Debye-Waller factor on going through the martensitic transformation. Unfortunately $\mathrm{Co}-7 \mathrm{wt}$ pet Fe does not in fact transform martensitically and the quoted concentration [26] must be incorrect. Shapiro and the present author did, however, explore the lattice dynamics of a Co-8 wt pct Fe crystal [27] and showed that fcc Co was nearly vibrationally identical to fcc Ni. They also developed the relevant phonon description of the fcc-hep transition in which they showed that only 2 static shear waves of opposite phase were needed to transform fcc into hep namely $1 / 6(111)$ polarized in $(\overline{112})$ and $1 / 3$ (111) polarized in (112) with amplitudes $1 / 6(111) / 1 / 3(111)=\sqrt{3}$. The two reciprocal lattices when superimposed show fcc flanked by satellites at these two wave vectors to produce hcp. Whether future neutron scattering will reveal instabilities or premonitory effects at these wave vectors remains to be seen.

6. Other selected cases and $\mathbf{N b}_{3} \mathrm{Sn}$. - Among the other selected cases are those alloys that happen, to this reviewer's knowledge, to have been studied with neutrons. These include $\mathrm{ZrV}_{2}(28), \mathrm{Fe}_{3} \mathrm{Pt}(29)$ and $\mathrm{Cu}_{2,8} \mathrm{Al}_{1.04} \mathrm{Ni}_{0.16}(30)$. The $\mathrm{ZrV}$ is a Laves phase studied by Moncton in a preliminary way with powder diffraction to show the structural transformation and its relation to superconductivity (a general theme developed for many of these alloys and thought important because of the competition in the electronphonon coupling between a superconducting state and a Pierls-type structural phase transition). In $\mathrm{Fe}_{3} \mathrm{Pt}$, an Invar (low thermal expansion) alloy, there is again an anomalous decrease in $\left(C_{11}-C_{12}\right) / 2$ as well as $C_{44}$. The structure is isomorphous with $\mathrm{Cu}_{3} \mathrm{Au}$ and is ferromagnetic below $500 \mathrm{~K}$. As the anomalous decrease in $\left(C_{11}-C_{12}\right) / 2$ sets in, a central (elastic) peak is seen to develop at the soft transverse wavevector and is attributed by the authors to some feature of the martensitic transformation that takes place at $\sim 60 \mathrm{~K}$. In the $\beta_{1}$ phase $\mathrm{Cu}-\mathrm{Al}-\mathrm{Ni}$ alloy there is a martensitic transformation from ordered fce to ortho- rhombic, a soft $\left(C_{11}-C_{12}\right) / 2$ and no neutron evidence by Hoshino et al. [30] for any premonitory or anomalous effects either in the dynamical or static response.

Finally we have $\mathrm{Nb}_{3} \mathrm{Sn}$, the canonical A-15 high temperature superconductor studied so successfully by Shirane and Axe [31, 32] and first shown to have a lattice transformation by Mailfort et al. [33]. The $\beta$-W structure is related to bcc with $\mathrm{Sn}$ atoms in bcc positions and $\mathrm{Nb}$ as chains along the cube faces in (100) directions which dimerize below the structural transition. The neutron scattering shows a dramatic temperature dependent softening of the (110) : (110) mode near the zone center, possibly driven by a small wavevector $2 \mathbf{k}_{\mathrm{F}}$ instability, and pronounced elastic or central peak intensity as the transformation is approached from above.

This is probably the most detailed neutron study of a martensitic transition which has revealed : $a$ ) a strong temperature dependent acoustic shear mode softening, $b$ ) an electronic origin for the instability, $c$ ) a temperature dependent central peak intensity due presumably to a coupling of the soft acoustic waves to other relaxation modes of the system.

Along with elucidating the mechanism of the transformation Axe and and co-workers [31, 32, 34] also discuss a possible static origin of the central peak intensity. They point out that defects, through the introduction of a static strain field, which is governed by the elastic constants of the crystal as well as the strength of the defect, will give rise to Huang scattering at, -say, small wave vectors which varies as $1 / w^{4}$, where $w$ is the frequency of the phonon at that wave vector. If $w$ is temperature dependent, the static Huang scattering will grow as $1 / w^{4}$ and will dominate the scattering as the structural transition is approached. This static defect model does not in fact explain completely the detailed quantitative response of $\mathrm{Nb}_{3} \mathrm{Sn}$, but a model qualitatively analogous to it must be invoked to explain the central peak intensity in the light scattering from KDP (potassium dihydrogen phosphate) which has been recently phoographed by Durvasula and Gammon [35] and which shows a static speckle. It may, therefore, be true that by invoking extrinsic defects, one may approach a static or domain model at least for structural phase transitions, that explains some of the more unusual neutron results. In such cases, the defect, serving as a strain center, produces a displacement field modulated by the soft wave vector which replicates many of the features of a nucleus or coherent domain embedded in the host lattice.

Acknowledgments. - It is a pleasure to thank my colleagues at Brookhaven : J. D. Axe, S. M. Shapiro and G. Shirane and at IIl, Grenoble : R. Pynn and W. G. Stirling for collaborations and discussions. Thanks also to L. Delaey for comments on $\mathrm{Cu}-\mathrm{Al}$ alloys. This general program of work has been supported by the U. S. ERDA. 


\section{References}

[1] Burgers, W. G., Physica 1 (1934) 561.

[2] ZeNER, C., Phys. Rev. 71 (1947) 846.

[3] Moss, S. C., Keating, D. T. and Axe, J. D., Solid State Commun. 13 (1973) 1465

[4] Fuchs, K., Proc. R. Soc. A 151 (1935) 585,; 153 (1936) 622; 157 (1936) 444.

[5] Mort, N. F. and Jones, H., Theory of the Properties of Metals and Alloys (Dover Publications reprint) 1958, pp. 147 150.

[6] Warlimont, H. and Delaey, L., progress in Materials Science 18 (Pergamon Press) 1974.

[7] Price, D. L., Singwi, K. S. and Tosi, M. P., Phys. Rev. B 2 (1970) 2983.

[8] PYNN, R. and Shapiro, S. M. (private communication).

[9] De Fontaine, D., Acta Met. 18 (1970) 275.

[10] Sanchez, J. M. and De Fontaine, D., J. Physique Colloq. 38 (1977) C7.

[11] Cook, H. E., Surjawa, M., Kamtani, T. and Rivaud, L., J. Physique Colloq. 38 (1977) C7.

[12] Moss, S. C., Keating, D. T. and Axe, J. D., in Phase Transitions, 1973, L. E. Cross, ed. (Pergamon Press, N. Y.) 1973 , p. 179.

[13] Axe, J. D., Keating, D. T. and Moss, S. C., Phys. Rev, Lett. 35 (1975) 530.

[14] Cook, H. E., Acta Met. 21 (1973) 1445; 22 (1974) 239.

[15] Fisher, E. S. and Renken, D. J., Phys. Rev. 135 (1964) A 482.

[16] Pops, H. and Massalski, T. B., Trans. Met. Soc. AIME 230 (1964) 1662.

[17] Moss, S. C., Axe, J. D. and Wayman, M., Bull. Am. Phys. Soc. 20 (1975) 286.
[18] Murakami, Y., J. Phys. Soc. Japan 33 (1972) 1350.

[19] MoRi, M., Yamada, Y. and ShiRane, G., Solid State Commun. 17 (1975) 127.

[20] Vatanayon, S. and Hehemann, R. F., in Shape Memory Effects in Alloys, A. J. Perkins, ed. (Plenum Press, N. Y.) 1975 , p. 115.

[21] Sandrock, G. D., Perkins, A. J. and Hehrmann, R. F., Met. Trans. 2 (1971) 2769.

[22] HehrmanN, R. F. and SANDrock, G. D., Scripta Met. 5 (1971) 801.

[23] PACE, N. G. and Saunders, G. A., Phil. Mag. 22 (1970) 73.

[24] Gunton, D. J. and Saunders, G. A., Solid State Commun. 12 (1973) $569 ; 14$ (1974) 865.

[25] Murakam, Y., J. Phys. Soc. Japan 38 (1975) 404.

[26] Bokshtein, B. S., Voltkovski, Yu. B., Nikol'skin, G. S. and RaZumovskil, I. M., Sov. Phys. JETP 37 (1973) 283.

[27] Shapiro, S. M. and Moss, S. C., Phys. Rev. B 15 (1977) 2726.

[28] Moncton, D. E., Solid State Commun. 13 (1973) 1779.

[29] Tajma, K., Endoh, Y., Ishikawa, Y. and Stmling, W. G., Phys. Rev. Lett. 37 (1976) 519.

[30] Hoshino, S., Shirane, G., Suezawa, M. and Kaitian, $\mathrm{T}$., Japan J. Appl. Phys. 14 (1975) 1223.

[31] Shmane, G. and Axe, J. D., Phys. Rev. Letet. 27 (1971) 1803

[32] AXE, J. D. and Shrrane, G., Phys. Rev. B 8 (1973) 1965.

[33] Mailfort, R., Batterman, B. W. and Hanak, J. J., Phys. Lett. 24 (1967) 315.

[34] Axe, J. D., Shapiro, S. M., Shirane, G. and Riste, T., in Anharmonic Lattices, Structural Transitions and Melting, T. Riste, ed. (Noordhoff, Leiden) 1974.

[35] Durvasula, L. N. and Gammon, R. W., Phys. Rev. Lett. 38 (1977) 1081. 